\title{
ORKUT E SERVIÇO DE ATENDIMENTO AO CLIENTE: ESTUDO DE CASO DO BOTICÁRIO
}

\section{Eduardo Picanço Cruz}

\section{Sabine Ott da Costa}

\section{RESUMO}

A democratização do acesso à internet, principalmente através de instrumentos de inclusão digital, tem gerado um aumento significativo nas trocas entre pessoas, mas, principalmente no que tange as relações cliente X empresa. Nesse sentido, os espaços virtuais (Orkut, blogs, etc.) estão deixando de ser ferramentas de conversa e troca de encontros pessoais e evoluem para uma nova forma de comunicação da empresa com o cliente e otimização dos processos organizacionais. Esta pesquisa investigou e analisou a utilização desses espaços virtuais como serviço de atendimento ao consumidor (SAC) pelas organizações. Uma pesquisa bibliográfica foi feita para investigar a forma como as empresas lidam com esses espaços, a fim de atingir seus objetivos e estratégias para continuar competitiva no mercado e com sua imagem consolidada. No aprofundamento da área foi feito um estudo de caso com a empresa OBoticário, a fim de exemplificar a investigação e análise em questão.

Palavras-Chave: Serviço de atendimento. Orkut. Espaços virtuais.

\begin{abstract}
Having in mind the constant Internet growth, it is noticeable that, more than ever, companies are seeing virtual spaces (Orkut, blogs etc) as new means of communication with the cliente and optimization of organizational processes. This research investigated and analyzed the utilization of these virtual spaces as consumer service information by organizations. A bibliographic research was done to investigate the way companies deal with these spaces in order to attain their objectives and strategies to keep competitive in the market with a consolidated image. A subject matter was done using the company $\mathrm{O}$ Boticário to exemplify the investigation and the analysis in question.
\end{abstract}

Key-words: Internet. Virtual spaces. Consumer service information. 


\section{INTRODUÇÃO}

Os espaços virtuais já se mostram importantes no dia-a-dia de muitas empresas, dessa forma, são vistos como oportunidade ou ameaça para seus negócios. Como as organizações têm se preocupado com sua imagem perante o mercado, sentem a necessidade de monitorar os espaços virtuais, a fim de captar informações que sejam úteis para manterem sua aceitabilidade e credibilidade no mercado.

Com o avanço de informática, aliada ao fenômeno da globalização, as organizações estão expostas e suscetíveis às opiniões de consumidores cada vez mais bem informados e familiarizados com a internet. Assim, as empresas procuram estar atentas aos espaços virtuais para colher informações e publicações advindas de consumidores e clientes sobre sua aceitabilidade e de seus produtos no mercado.

Nesse sentido a pergunta básica que leva aos estudos foi: as empresas têm observado que os canais não tradicionais de comunicação, como blogs e comunidades do Orkut podem virar o novo SAC? 0 estudo buscou a influência de ferramentas como o Orkut na comunicação com os clientes de organizações privadas e nacionais, relacionada com a imagem perante a sociedade.

\section{GESTÃO DE MARKETING}

A boa prática do marketing consiste em planejar, contemplando e promovendo a melhoria contínua dos processos, com atenção para a função social de atendimento aos desejos e necessidade das pessoas, proporcionando satisfação, bem-estar e qualidade de vida aos indivíduos e à sociedade (LEITE, 2006).

No atual ambiente competitivo, as empresas devem ficar atentas às mudanças para manterem sua sobrevivência. Nesse contexto, é evidente que a preocupação com os esforços de marketing nas organizações estejam voltados para vários aspectos, porém, o primeiro deles é ter bem definida a missão e a visão de negócios, para as empresas terem uma direção a seguir dentro do mercado e poder dar ênfase em seus processos. Entretanto, é preciso formular e implementar estratégias com base nos objetivos e metas organizacionais para manter um direcionamento, também faz-se necessárias as pesquisas, coletas e analises de informações para identificar necessidades do mercado e comportamento dos consumidores. Uma empresa bem informada é capaz de se adaptar às mudanças rapidamente para aproveitar as oportunidades e inovações do mercado.

Cabe ressaltar, por fim, a evidência que já vem sido discutida nas últimas décadas sobre a preocupação com os clientes a fim de manter um bom relacionamento, dessa forma, também importante acompanhar os movimentos estratégicos da concorrência, a fim de não descuidarse das necessidades dos clientes.

\section{CRM}

CRM é um acrônimo de origem inglesa Customer Relationship Management que significa em português, Gestão de Relacionamento com o Cliente. É uma sigla que se tornou notória no final dos anos 90 e que atualmente é apontada como o novo e inevitável caminho para a sobrevivência nos negócios, pois o cliente precisa ser visto por todos os departamentos da mesma maneira e a comercialização deve estar focada nas necessidades de cada consumidor (SOUZA, 2003).

Para o presidente da Peoplesoft, Conway (apud GREENBERG, 2001), para que o CRM seja 
efetivo é preciso estar integrado a todos os processos que constituem o funcionamento da organização e ajudar as pessoas a tomarem mais rápidas e melhores decisões. É preciso também direcionar mais energia para os clientes insatisfeitos, no sentido de tentar mantê-los, do que para os clientes que estão satisfeitos, já que esses têm menor probabilidade de abandonar a empresa. Além disso, o bom programa de CRM deve estar acessível a todas as pessoas envolvidas em processos que influenciem as percepções dos consumidores, garantindo informações corretas sobre eles, seus valores e suas necessidades. Dessa forma, ele se torna uma estratégia disciplinada de negócios, voltada a criar e sustentar relações que gerem lucro de longo prazo com os clientes. Com as estratégias e filosofia da empresa, alinhadas com as necessidades dos clientes, é possível ter um CRM bem sucedido, já que a tecnologia CRM proporciona a transformação de estratégias em resultados.

O CRM tradicional oferece um conjunto de ferramentas que não foram desenhadas para Web e que são direcionadas somente para os funcionários ou departamentos da organização. Com isso, surgiu o eCRM, que é um meio adicional de comunicação e em outro nível de interação, que permite ao cliente o auto-serviço, oferecendo experiência total na Web. Ou seja, eCRM é a parte do CRM que funciona como uma interface com o cliente na Internet, o que vai gerar maior interação com a empresa.

Segundo Souza (2003) a maioria das empresas está preocupada com a crescente infidelidade dos clientes, aumento da concorrência e globalização. Entretanto, o CRM implica em uma mudança na filosofia dos negócios, na postura de trabalho da organização, de seus dirigentes e colaboradores, além de mudanças culturais profundas que muitas vezes reorganizam toda a empresa.

Para Soares (2006) alguns softwares que auxiliam e apóiam a gestão de relacionamento com o cliente são comumente classificados e denominados como sistemas de CRM. O CRM abrange, na generalidade, três grandes áreas: Automatização da gestão de marketing; Automatização da gestão comercial, dos canais e da força de vendas. Segundo Monti (2002) no atual século da revolução da informação, o cliente está mais informado, ansioso e querendo ser cada vez mais bem atendido, objetivando ser o "único". Assim, pode ser facilmente atraído pela concorrência sem muito esforço, já que é bombardeado milhares de vezes por dia com informações de produtos e serviços dos mais variados, tornando então mais difícil a sua decisão de compra, devido ao grande número de fornecedores existentes em todos os segmentos de negócios.

Para Bender (2006) o CRM é fundamental para monitorar o hábito de compra, entradas e saídas e atendimento, o que permite entender a periodicidade com que o cliente se relaciona com a empresa e suas características de consumo. Além disso, algumas tendências do mercado podem ser captadas dos números trazidos pelos softwares. Assim, além de gerenciar o relacionamento com o cliente, deve-se gerenciar a experiência que o cliente tem com os produtos, serviços e marcas. Então, pode-se entender o CRM como uma ferramenta para fidelizar clientes, que procura atingir a satisfação total deles através do melhor entendimento de suas necessidades e expectativas, atraindo e mantendo-os junto à marca, nome, produtos e serviços com o fornecimento de um bom relacionamento, já que buscam comodidade, conveniência e prazer em contatar a empresa.

Barella (2001) ressalta que os investimentos da maioria das empresas em processos internos de ERP e CRM sinalizam que o mercado vai continuar a investir no seu maior patrimônio que é o cliente. Este é o momento da revolução do relacionamento e não mais da informação. Em paralelo ao CRM, as centrais de relacionamento, geralmente conhecidas como SAC (Serviço de Atendimento ao Consumidor) tem por finalidade, atender os clientes das organizações, 
esclarecendo suas dúvidas, solucionando seus problemas e ouvindo as reclamações e sugestões, com um atendimento de qualidade. Entretanto, antigamente havia uma enorme barreira entre indivíduos e empresa, o que desestimulava o fluxo de mensagens entre ambos e o atendimento era praticamente nulo. A reclamação de um consumidor ao fabricante, por exemplo, exigia o envio de cartas, que poderiam levar meses até chegar às mãos adequadas. Com a disseminação do fax, a multiplicação das linhas telefônicas, a banalização do PC e, finalmente, o surgimento da Internet, possibilitaram o fluxo de informações em poucos anos.

Segundo Moreira de Sá (2003) há quem atribua ao novo fluxo de interações indivíduo empresa, o amadurecimento de dispositivos como o Código de Defesa do Consumidor, já que sem este seria praticamente impossível o surgimento do SAC, que é um importante requisito para o cumprimento do Código. Atualmente, o cliente ao procurar atendimento em um call center de uma empresa, é muito mais "conhecido" do que o seria sem os sistemas automáticos de mapeamento estatístico, que disponibilizam ao atendente o histórico de contatos realizados, os principais pontos de insatisfação do tal cliente e até mesmo o seu nível de fidelidade à empresa. Assim, ter todos os dados do cliente disponível em todos os departamentos, ter a capacidade de analisar estes dados e finalmente transformar estes dados em informações úteis,é fundamental para uma ação mais eficiente, além da empresa poder conhecer todos os seus tipos de clientes (KENDZERSKI, 2006)

O conceito e as facilidades dos call centers tem se ampliado e tornado mais abrangente, até passando a ser chamado de contact center, já que o "centro de contato" do cliente com a empresa, pode receber as solicitações e reclamações por telefone, fax, e-mail, internet e etc (BARELLA, 2001). Pallotta (2006) destaca que uma vantagem que torna eficiente a integração desses diversos meios entre si, é que o cliente ao trocar de canal de comunicação, não é obrigado a contar a mesma história a cada interação, já que se tem todas as informações registradas.

\section{ESPAÇOS VIRTUAIS}

A Internet é a principal das novas tecnologias de informação e comunicação, pois é um conglomerado de redes em escala mundial de milhões de computadores interligados que permite o acesso a informações e todo tipo de transferência de dados. Em outras palavras, é uma rede de redes, onde cada rede individual conectada à Internet pode ser administrada por uma entidade governamental, uma empresa (como os provedores de acesso) ou uma instituição educacional que permite o acesso remoto (das residências via conexão discada) e administra a LAN (local area network) ou rede local. As redes que formam a Internet são interligadas por outras redes de alta capacidade, chamadas backbones (computadores poderosos conectados por linhas de grande largura de Banda, como canais de fibra óptica, elos de satélite e elos de transmissão por rádio). Assim, para que todos os computadores conectados possam trocar informações independentemente do tipo de hardware ou sistema operacional instalado, precisam utilizar uma linguagem comum que é formada por dois componentes o TCP (Protocolo de Controle de Transmissão) e o IP (Protocolo Internet) conhecida como TCP/IP.

As empresas estão cada vez mais criando websites para utilizá-los como "cartão de visitas", canal de comunicação e interação com o consumidor, além de fácil meio de divulgação da marca, já que é possível aumentar sua visibilidade com anúncios virtuais de diversos tipos.

Cabe ressaltar, que os usuários de internet vêm aumentando a cada instante e os consumidores já perceberam que podem encontrar as informações que desejam e podem 
interagir com as empresas da maneira que quiser, podendo efetuar contatos diretos e obter retorno imediato, além de conhecer melhor a marca da empresa, seus produtos e serviços (MERINO, 2006).

Segundo Kotler (2000) as ferramentas de busca da Internet, deixam os consumidores bem informados e perspicazes em relação ao mercado, já que proporcionam a capacidade de comparação diante da variadas informações objetivas sobre empresas, produtos, marcas, preço, atributos e qualidade. Ou seja, nessa nova era da informação, os clientes que iniciam e controlam o seu processo de compra, definindo que tipo de produto ou serviço atende às suas necessidades. Esses serviços de compra e venda on-line têm se tornado populares, pois fornecem benefícios como conveniência, informação e comodidade. Entretanto, as empresas também ganham vantagens com isso, já que podem se ajustar às condições do mercado rapidamente, construir bom relacionamento com os clientes, calcular e determinar o número de visitas ao site, além de reduzir seus custos ao não optar pelo meio tradicional de venda.

Por outro lado, existe um ponto negativo para as empresas em relação a essa diver sidade de informações. Antes da Internet, os clientes não tinham um fácil acesso às pessoas que adquiriram produtos ou serviços da mesma empresa que estavam pensando em adquirir.

Todavia, com a internet, surgiram fóruns, grupos e listas de discussão, salas de bate-papo, boletins informativos ou até mesmo, comunidades na web que abordam os mais variados tipos de assunto, inclusive relacionados às empresas e seus respectivos produtos e serviços. Isso dá a oportunidade aos consumidores e aos concorrentes de formarem e expressarem suas opiniões, além de terem a chance de conversar, falando bem ou mal das organizações, produtos e serviços em questão (FIORE, 2001)

Com isso, as organizações ficaram suscetíveis a qualquer tipo de comentário, beneficiando ou não, sua marca e sua reputação perante o mercado. Assim, surge a necessidade das empresas começarem a monitorar e a levar a sério essas opiniões para poderem repensar em relação a tais questões.

\section{Orkut}

0 Orkut é um site de relacionamento filiado ao grupo Google, criado em 22 de Janeiro de 2004 com o objetivo de ajudar seus membros a criar novas amizades e manter relacionamentos, ou seja, é um grande banco de dados sobre rede de amizades. Seu nome é originado no projetista chefe, Orkut Büyükkoten, engenheiro turco do Google (TELLES,2006).

O Orkut é definido como uma comunidade online desenvolvida para promover a interação entre as pessoas, estabelecer relacionamentos e criar comunidades em torno de interesses comuns. Já que a equipe do site quer manter o Orkut uma comunidade íntima de amigos, não é possível incluir imediatamente todos os interessados em participar. Contudo, cada usuário só pode obter uma conta, também chamada de perfil, a partir de um convite de um amigo participante da rede. Cada pessoa possui um perfil dividido em três partes: Social ou Geral, que apresenta características pessoais como preferências de livros, músicas, programas de TV, filmes, entre outras; Profissional, que está relacionado com a profissão que exerce e informações sobre estudos e carreira; e Pessoal, com levantamento das características que facilitam relações interpessoais, ressaltando informações físicas, além de citar características de um parceiro ideal para se relacionar. Cada perfil também apresenta uma página de recados, do inglês chamado de scrapbook, onde os amigos podem escrever o que quiserem, como por exemplo, um lembrete de festa ou mesmo perguntar sobre novidades. Já que os 
recados (scraps) ficam expostos ao público, cabe ao usuário a decisão de mantê-los ou eliminá-los para manter sua privacidade (TELLES, 2006).

Em relação às amizades, cada usuário tem um grupo de amigos que pode chegar a 1.000 pessoas no máximo, sendo estes classificados como desconhecido, conhecido, amigo, bom amigo e melhor amigo. No mesmo estilo desta, outra classificação é feita através de símbolos que caracterizam o amigo como confiável (smile), legal (cubo de gelo) e sexy (coração), sendo esses em três níveis de intensidade, se possui ou muito ou demais tal característica.

Essas classificações são confidenciais, ou seja, dono do perfil as edita a hora que quiser, mas o amigo adicionado não sabe quais foram suas atribuições. Entretanto, no perfil aparece a classificação relacionada a cada símbolo em forma de porcentagem. Uma outra opção encontrada pelo usuário é se declarar fã através de outro símbolo, uma estrela amarela. $\mathrm{Na}$ página principal é possível acessar a lista de fãs que cada um possui, sendo assim uma opção visível para todas as pessoas.

O Orkut possui comunidades que podem funcionar como fóruns de interesses comuns e os usuários optam por entrar ou só acompanhar. Tais comunidades não possuem limite de participantes, entretanto cada usuário pode adicionar 1000 comunidades, no máximo. Várias pessoas podem participar das diversas comunidades existentes, podendo discutir qualquer assunto relacionado ao tema proposto. Nas comunidades existem duas áreas de interação: o fórum e os eventos. 0 primeiro funciona por meio de tópicos, onde uma pessoa expõe um tema com sua opinião para gerar uma discussão e outros usuários podem responder ao tópico logo abaixo. No segundo, as pessoas têm informações de eventos, como festas, palestras, congressos, etc. que ocorrerão em algum lugar com tema relacionado à comunidade.

O site também tem um grande sistema de busca de amigos e de comunidades. Os usuários buscam amigos que desejam encontrar através de informações como nome, idade, etnia, orientação sexual, visão política, aparência, dentre outros. Já a busca de comunidades, que os usuários podem escolher participar, é feita por nome, idioma ou através de 28 categorias propostas pelo site. Dentre essas, pode-se destacar Atividades, Alunos e Escolas, Artes e Entretenimento, Automotivo, Negócios, Cidades e Bairros, Empresa, Computadores e Internet, Países e Regiões, Culturas e Comunidade, Família e Lar, Moda e Beleza, Culinária, Bebidas e Vinhos, Jogos, GLS (Gays, Lésbicas e Bi), Governo e Política, Saúde, Bem-estar e Fitness, Hobbies e Trabalhos Manuais, Pessoas, Música, Animais de estimação ou não, Esportes e Lazer, Religiões e Crenças, Romances e Relacionamentos, Escolas e Cursos, História e Ciências, Viagens e outras. Cada categoria conta com centenas, ou até milhares de comunidades dos mais variados assuntos.

Segundo informações disponíveis nesse site o Orkut possui mais de 10 milhões de usuários cadastrados no mundo. De acordo com os dados extraídos do Orkut em 28 de outubro de 2006, as pessoas mais jovens são as que têm mais interesse no Orkut, sendo aproximadamente $61,58 \%$ entre 18 e 25 anos. Entretanto esse número não é real, já pessoas menores de 18 anos, proibidos de participarem da rede, colocam idades incorretas ou nem fornecem a data do nascimento. Um número que apresenta maior exatidão é o das pessoas entre 26 e 30 anos, que ficam em segundo lugar de participação, com 12,41\%. Em geral, $74,27 \%$ das pessoas que ingressam no site, tem como maior objetivo encontrar amigos antigos e fazer novas amizades e $25,36 \%$ dos participantes procuram contatos profissionais.

Outra informação importante é que o Brasil é o país com o maior número de membros, com cerca de 62,54\%, aproximadamente 18 milhões de usuários do sistema, superando inclusive 
os Estados Unidos da América com cerca de 14,12\%, o equivalente a 3,8 milhões de usuários. Em terceiro lugar aparece a Índia, com uma fatia de 10,53\%.

Todavia, esses números não apresentam muita exatidão, já que tem base em informações fornecidas pelos usuários durante o preenchimento do cadastro do site. É muito comum o usuário criar mais de um perfil ou o usuário de um país se cadastrar como se residisse em outro, seja por ter mais afinidade com outro país ou até motivados por mitos, como o que surgiu que se declarasse ser de um outro país que não fosse Brasil o sistema ficaria mais rápido e erros diminuiriam. Isso foi provado mentira, o sistema ficava lento somente em horários de pico. Como já supracitado, o Orkut faz muito sucesso entre os jovens. Entretanto, oportunidade de deixar uma mensagem com vários problemas levam muitos usuários a cometerem o Orkutício, uma espécie de suicídio virtual, ao excluir a conta (TELLES, 2006).

A perda de privacidade é um problema encontrado no Orkut já que este é público e qualquer um pode visitar o perfil. Como exemplo, conflitos em relacionamentos acabam surgindo devido à espionagem rotineira de parceiros, que pedem satisfação de recados deixados ou participação em certas comunidades. Até muitas empresas já começaram a espionar os perfis de candidatos às vagas abertas, para conseguir informações adicionais sobre eles (TELLES,2006).

A falta de materialização dos relacionamentos estabelecidos e restabelecidos através da rede também contribui para exclusão da conta, já que várias pessoas pedem para serem adicionadas para fazerem amizade e nunca mais aparecem. Além disso, vários perfis falsos são criados com o objetivo de difundir material ilegal, fazer alguma brincadeira com celebridades, permanecer no anonimato vasculhando a vida alheia para planejar roubos ou seqüestros, ou mesmo criar intrigas. Do mesmo modo, várias comunidades preconceituosas são criadas, além de outras para fazer apologias às drogas e à pedofilia.

Outro fator que inferniza a vida dos usuários é a grande quantidade de spam, que são mensagens eletrônicas enviadas através dos scraps para todos os amigos ou membros de determinada comunidade. Dessa forma, muitas pessoas, candidatos políticos ou até mesmo empresas têm utilizado o Orkut com uma ferramenta de marketing, usando a propaganda de forma inadequada.

\section{OS ESPAÇOS VIRTUAIS VISTOS COMO SAC}

Em contrapartida ao fenômeno Orkut como rede de amizades, várias comunidades virtuais foram criadas para focar em relacionamentos profissionais. Os fóruns são utilizados para discussão de temas pertinentes às áreas profissionais não havendo espaço para formalidade e nos eventos são postados horários e locais de cursos, palestras e congressos a serem realizados. Diferente de outras comunidades, nestas existem políticas de moderação e regras de conduta bem definidas.

Partindo da iniciativa de funcionários ou de admiradores (ou não) de determinada marca, comunidades de empresas são criadas para discutir sobre seus produtos e serviços. Com a era da informação, os clientes estão cada vez mais à procura de informações, principalmente via web, antes de comprar um determinado produto e um consumidor tem influência sobre dezenas de outros. Assim, procuram saber preços, características, aparecimento de defeitos, etc. O surgimento de comunidades com fóruns de discussão, facilita a busca dessas informações, já que se dá de maneira rápida e descontraída.

Com a grande repercussão do Orkut, várias empresas começaram a pesquisar nas 
comunidades relacionadas aos seus nomes, o que os consumidores estavam pensando e dizendo sobre aquilo que forneciam. As organizações começaram a perceber que podem utilizar esse site para captar informações do que é necessário fazer para ter boa aceitação de seus produtos no mercado e o que podem fazer para aperfeiçoá-los para atender às necessidades e os desejos dos clientes.

O mesmo tem acontecido com os blogs. Os usuários desses espaços virtuais têm abordado diversos assuntos, entre eles assuntos referentes aos produtos ou serviços fornecidos pelas empresas. Como nesses espaços os usuários têm liberdade para expressarem sua opinião, podendo fazer críticas destrutivas ou construtivas várias empresas têm a oportunidade de monitorar esses comentários, para poderem reformular seu portfólio ou estratégias. Assim, para as empresas suprirem tais necessidades de informação sobre sua imagem, produtos e serviços na internet, atualmente, têm como opção contratar o serviço de terceiros.

Em 2004, a E-life surgiu como uma empresa brasileira especializada, em monitorar e analisar a comunicação boca-a-boca sobre marcas, produtos e serviços a partir de comunidades online, blogs, sites pessoais, Orkut, fóruns e outros lugares onde ocorram de forma pública diálogos espontâneos de consumidores.

Os serviços desta consultoria são utilizados como:

- Pesquisa: estudos de mercado a partir da monitoração de depoimentos espontâneos de consumidores;

- Serviço de Atendimento ao Consumidor: Monitoração de depoimentos espontâneos de consumidores para alimentação do SAC e monitoração de feedback e clientes;

- Planejamento: Desenvolvimento de estratégias / inteligência de mercado e gestão de crises a partir da monitoração do boca-a-boca e identificação dos formadores de opinião.

Os métodos utilizados pela empresa são:

- Monitoração do boca-a-boca espontâneo de consumidores sobre marcas, produtos e serviços;

- Desenvolvimento de análises qualitativas e quantitativas dos dados recolhidos, utilizando métricas próprias e reconhecidas mundialmente: classificação multidimensional da performance da comunicação boca-a-boca (ex. negativo, positivo, neutro, "em busca de resposta", etc.); identificação de formadores de opinião com influência sobre assuntos específicos com base na densidade de rede; e recomendação de ações para estimular o boca-aboca ou melhorar o sentimento dos stakeholders sobre os tópicos monitorados;

- Entrega de análises científicas da comunicação boca-a-boca com a utilização de métricas específicas. 
Figura 1: Site e-life

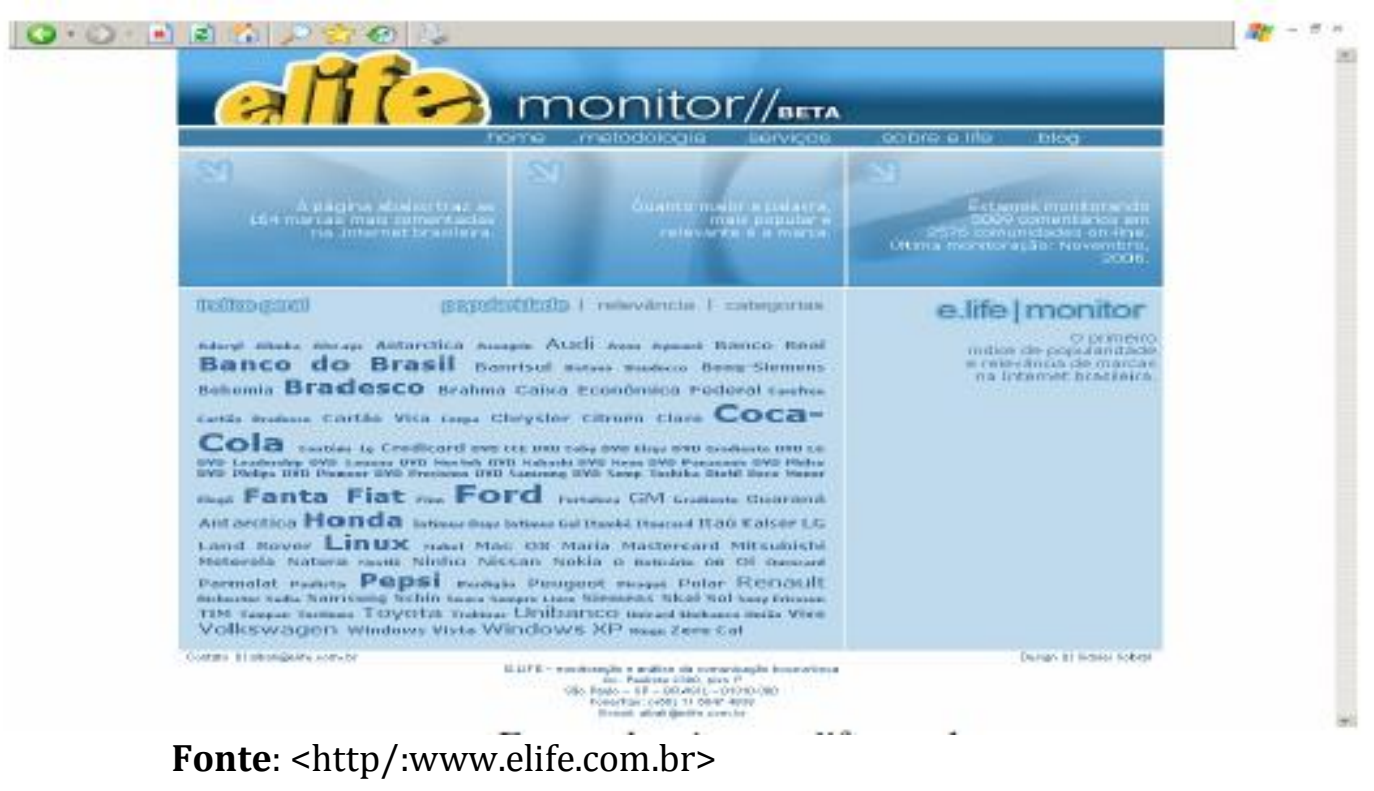

O E-life Monitor tem como objetivo ser a primeira medida de popularidade e relevância das marcas na Internet brasileira nas principais categorias do mercado de consumo como alimentos, bancos, perfumes, entre outros. Além disso, oferece uma medida confiável do que é falado por milhões de consumidores brasileiros em blogs, fóruns e comunidades online, a partir da monitoração da comunicação boca-a-boca online, interpessoal e de caráter espontâneo. É uma referência essencial para as empresas, já que oferece uma visão do desempenho de cada marca no segmento da população com acesso à Internet, que é um dos que mais cresce no país e que representa uma parcela significativa dos formadores de opinião entre os consumidores.

Para o cálculo do índice, o E-life Monitor utiliza o Google e o Yahoo!, que são os dois mais populares mecanismos de busca entre os internautas brasileiros, para calcular o índice de popularidade e relevância de cada marca. Cerca de 60 serviços entre blogs, comunidades, fóruns e outros, são consultados para a formação de um índice que é tomado com base nas opiniões espontâneas (positivas ou negativas) que os internautas expressam em comunidades virtuais da Internet brasileira. Quanto maior o número de referências espontâneas (boca-aboca) a uma determinada marca entre os depoimentos monitorados, maior é o seu índice de popularidade no E-life Monitor. 0 cálculo leva em consideração o número de referências a cada marca nos dois buscadores (Google e Yahoo!) e faz uma média ponderada de acordo com a penetração de cada buscador no mercado brasileiro.

0 índice de relevância também utiliza ambos buscadores para formação do índice. Neste caso, são analisados os incoming links que cada referência retornada possui. Os incoming links são links que outros sites fazem àquele site onde a referência à marca foi encontrada. Quanto maior o número de incoming links, maior a probabilidade daquele site ser encontrado por outros internautas e portanto mais relevante o comentário nele encontrado. Assim, enquanto o índice de popularidade representa uma medida de quantas pessoas estão falando de uma determinada marca, o índice de relevância representa uma medida de desempenho daquela marca entre os formadores de opinião espalhados pela Internet brasileira.

Cabe ressaltar que, o índice de popularidade e relevância disponibilizado gratuitamente no Elife Monitor não informa o caráter dos comentários encontrados e nem traduzem 
necessariamente o sentimento do internauta em relação àquela marca, mas sim o volume de comentários espontâneos encontrados. 0 sentimento do internauta pode ser analisado para cada caso, bastando para isso que a marca citada entre em contato com a empresa. Para ajudar as marcas brasileiras, a E-life disponibiliza relatórios mensais do sentimento dos consumidores em relação às marcas monitoradas.

A E-life, a empresa responsável pelo índice E-life Monitor, oferece serviços específicos para organizações que querem compreender o teor e a extensão da comunicação boca-a-boca sobre suas marcas. Para isso, a E-life comercializa relatórios mais detalhados sobre o posicionamento de suas marcas na Internet Brasileira.

\section{ESTUDO DE CASO: O BOTICÁRIO}

\section{Relacionamento Com 0 Cliente 0 Boticário}

De acordo com o relato da empresa o objetivo dessa equipe é manter um bom relacionamento com o cliente, contribuindo em cada contato para a conscientização dos seus direitos e deveres nas relações de consumo. Representá-lo perante a organização, além de posicionar a empresa sobre seus desejos, bem como, assegurar a valorização da marca com rentabilidade.

Para tal, são desenvolvidas as seguintes atividades:

- Ouvir atenta e criticamente os clientes e transformando as informações coletadas em base para desenvolver ações estratégicas;

- Orientar os clientes, tendo total conhecimento do que está ocorrendo na Empresa;

- Envolver as diversas áreas internas da Empresa nas questões trazidas pelos clientes, possibilitando o aperfeiçoamento dos produtos e serviços oferecidos;

- Realizar acompanhamento dos produtos antes e após o lançamento, analisando a reação dos clientes, identificando e prevenindo eventuais problemas, repassando as informações as outras áreas da empresa;

- Desenvolver atividades integradas com o Marketing: realização de pesquisas com franqueados e clientes finais, divulgação das promoções e dos lançamentos, etc.;

- Manter contato periódico com órgãos de Defesa do Consumidor e participar de associações e comitês da área de Atendimento ao Consumidor;

- Estabelecer lealdade e proteção à marca, pelos aspectos de segurança, respeito aos direitos do consumidor e de qualidade;

- Estabelecer uma comunicação única e personalizada com os clientes, independente da cidade de procedência e do assunto que gerou o contato;

- Facilitar o acesso dos consumidores ao fabricante, solucionando reclamações com rapidez e eficácia.

A empresa já ganhou vários prêmios relacionados a essa área o que comprova a percepção do mercado que o Boticário atua pro-ativamente em relação a seus clientes. Ela venceu, por exemplo: o VII Prêmio Consumidor Moderno de Excelência em Serviços ao Cliente, categoria "cosméticos" (Abril de 2006) e o VI Prêmio Consumidor Moderno de Excelência em Serviços ao Cliente, sendo eleita como uma das cinco melhores empresas de todos os segmentos, nos 
últimos 10 anos (2005).

Em 2005 seu site apresentou os seguintes indicadores de atendimento:

- Informação e elogio: 161.542, 49\% do total;

- Solicitações: 107.041, 33\% do total;

- Reclamações e denúncias: $39.715,12 \%$ to total;

- Outros: $20.924,12 \%$ do total.

\section{Monitoração Através Dos Espaços Virtuais}

Em 2005 O Boticário começou a notar a queda no número de contatos telefônicos dos consumidores e com isso voltou suas atenções para a internet. Ao mesmo tempo em que os telefonemas e cartas diminuíam, a empresa percebeu um crescimento de $40 \%$ no número de e-mails recebidos. 0 primeiro passo foi contratar uma empresa especializada, a E-life, para fazer um mapeamento da rede e uma monitoração do boca-a-boca online para alimentação da Central de Relacionamento do Consumidor com questionamentos em canais não-tradicionais, como comunidades, blogs, fotoblogs para se descobrir o que se falava a respeito dos produtos.

Com isso, encontrou várias comunidades criadas em seu nome em sites de relacionamento. Entre elas, uma comunidade no Orkut que se chamava "Sou órfã do One of Us", um perfume que já havia sido tirado de linha. Com o e-mail da moderadora do grupo em mãos, 0 Boticário entrou em contato e explicou o motivo da retirada.

O Boticário rastreia o Orkut e a blogosfera uma vez por mês e a empresa passou a contatar os consumidores que levantam questões ou fazem reclamações sobre as marcas e seus produtos. A empresa mudou, por exemplo, a válvula de um de seus perfumes que não funcionava direito, segundo os internautas. A companhia destaca que monitora essas manifestações espontâneas dos clientes, para aprender continuamente, no sentido de antecipar tendências e construir a cada dia uma nova empresa para o futuro. Dessa forma, o aprofundamento da pesquisa se deu através do monitoramento, durante o ano de 2006, dos espaços virtuais que dedicam comentários a empresa 0 Boticário. Uma equipe de 3 pessoas dividiu os sitesidentificados na investigação inicial e passaram a arquivar os comentários. Seguem alguns exemplos do que foi encontrado, mantendo a grafia e a forma usada pelos internautas.

Quadro 1: Comentários disponíveis monitorados pela e-life

\footnotetext{
- "É difícil conseguir pensar numa coisa interessante que não seja um perfume do Boticário ou qualquer outro cosmético. Me ajudem! ...";

- "Perfume do Boticário 8. Velas ou sabonetes especiais 9. Se for de 1,99 é relógio ou porta-retrato 10. Meu amigo secreto é alguém super legal, bacana,...”;

- "Teve um ano, há bastante tempo atrás em que Papai pegou uma colega no amigo-secreto que pediu um perfume do Boticário. Assim que ela colocou isso na lista ...";

- "Apesar do penteado à la Sarajane daquela secretária flatulenta do escritório e do sub-gerente pobre que exala perfume do Boticário, é fundamental manter a ...";

- "E COM PERFUME DO BOTICÁRIO AINDA POR CIMA... AGORA ELE TÁ FILÉ! CHEIROSO E FUNCIONANDO... SÓ TORÇO PARA QUE ISSO NUNCA ACONTEÇA NOVAMENTE CONOSCO!”;

- "Os números vermelhos alternavam lá em cima, a mistura dos cheiros dos outros, café, cigarro, hálito, desodorante Axe, perfume Boticário, a porta do elevador ...”;

- "De anúncios publicitários mostrando que ele só será alguém, se ele tiver um perfume Boticário , que ele só terá uma mulher se comprar um Fiat ....".
} 
Tabela 1: Pesquisa do E-life relacionada com a popularidade da marca (2006)

\begin{tabular}{|c|c|}
\hline \multicolumn{2}{|c|}{ Perfumes } \\
\hline Natura & $50,48 \%$ \\
\hline Avon & $32,38 \%$ \\
\hline O Boticário & $17,14 \%$ \\
\hline Contém 1g & $0 \%$ \\
\hline
\end{tabular}

Fonte: <http/:www.elife.com.br>. Obs: De acordo com o e-life, entende-se como popularidade o número total de menções em comunidades on-line

Tabela 2: Pesquisa relacionada com a relevância da marca (2006)

\begin{tabular}{|c|c|}
\hline \multicolumn{2}{|c|}{ Perfumes } \\
\hline Natura & $90,10 \%$ \\
\hline Avon & $9,66 \%$ \\
\hline O Boticário & $0,24 \%$ \\
\hline Contém 1g & $0 \%$ \\
\hline
\end{tabular}

Fonte: <http/:www.elife.com.br>. Obs: De acordo com o e-life, entende-se como relevância a relação da popularidade com a importância (medida por acessos) do site.

A comunidade no Orkut "O Boticário - oficial”, é usada como SAC, já que consultoras que pertencem à comunidade, respondem, no fórum, as dúvidas dos clientes:

Quadro 2: Usuário X (postado em 01/09/2006 as 19:46)

Assunto: Linha Active.

"Alguém usa ou já usou a linha Active? Estou procurando uma linha de produtos para pele oleosa e gostaria de saber se a linha do Boticário é boa. Acabei de ter bebê e tem alguns produtos de tratamento facial que năo posso usar, entăo estou procurando produtos que năo façam mal ao meu bebê."

$\rightarrow$ Resposta da consultora A (postado em 02/09/2006 as 05:02):

"A linha Active é maravilhosa e eficaz! Năo tenho dúvidas do que vc está procurando nossa linha vai satisfaze-la. È maravilhosa! E tem produtos completos e com ação inteligente para seu tipo de pela! Produtos que vão deixar sua pele com efeito mate (sem blilho) logo na $1^{\mathrm{a}}$ aplicaçăo!!! Mas como vc acabou de ganhar seu bebezinho, consulte seu dermatologista e veja qual produto na linha seria melhor para sua pele!"

Quadro 3: Usuário Y (postado em 20/09/2006 as 12:04)

\begin{abstract}
Assunto: Linha Vitactive.
"Gente, alguém já usou algum tipo de produto dessa linha? Estou procurando um creme, um sabonete facial e um creme anti idade e vi os dessa linha, mas năo sei se são realmente bons..."

- Resposta da consultora A (postado em 20/09/2006 as 20:13):

“ Oi ... sou consultora do Boticário e realmente dá efeito. Algumas clientes nossas testaram e aprovaram, vc nota os resultados em menos de uma semana ... sua pela fica mais vibrant ... A linha d tratamento facial do Boticário anti sinais é dividida assim ... 30+, 45+ e 55+ q săo por idades. Eles são creme diurnos e têm fator de proteçăo 25 , temos o noturno tb que é para complementar o tratamento, esse é para todas as idades por igual ... Na linha d limpeza temos um mousse purificant ideal para pele oleosa a mista, ele serv como sabonet líquido mas na forma de mousse, temos o tonico tb tanto para pele mista a oleosa, qnto para pele normal a seca ... Temos tb o ccreme area d olhos q é ótimo e esse eu uso e adoro de paixăo ... ele diminui as orelhas dando aspecto d vitalidad e renovaçăo da pele e tb é anti sinais, ou seja, diminui e evita as linhas d expressões q são mas fáceis d acontecer na área dos olhos ... Bom espero ter $t$ ajudado qnto a sua duvida...Agora vc decid ... abracao, qualquer duvida só me deixar um scrap ... T+"
\end{abstract}

Entretanto, uma outra consultora da empresa colocou um comunicado de proibição no fórum da comunidade supracitada: 


\title{
Quadro 4: Comentário da consultora na íntegra
}

\begin{abstract}
Comunicado de proibiçāo: RELACIONAMENTO NO MUNDO VIRTUAL. O mundo da tecnologia, o acesso e o relacionamento com os mais variados canais de comunicaçāo exigem procedimentos específicos. Com o objetivo de preservar a imagem de nossa marca e a reputaçāo de nossa empresa e produtos, elaboramos um código de conduta que deve ser seguido por nossos colaboradores, franqueados e equipes no mundo virtual, sempre que houver mençāo à marca $\mathrm{O}$ Boticário.

Listamos abaixo, os principais canais e a conduta que deverá ser adotada:

Canais

- Blog: sites interativos que permitem que o visitante inclua comentários sobre determinado assunto, deixando-o disponível para visualização de todos os outros visitantes. Geralmente os comentários partem de um post (mensagem publicada) incluído pelo proprietário do blog.

- Sites de Comunidade: o site de comunidade mais conhecido é o Orkut, que deu origem a outros parecidos como: UOLkut, Terra gaia e Beltrano. São sites que reúnem pessoas em comunidades regidas por interesses em comum, e também por meio de listas pessoais de afinidade.

- Messengers: sāo aplicativos instalados no computador que permitem a conversaçāo em tempo real, assim como chats. Entre outras funcionalidades o messenger permite: envio de vídeo, troca de arquivos, a realizaçāo de conferência. Mais usados: MSN, ICQ.

Nossa Conduta

Para as comunidades criadas pelos clientes (Orkut, UOLkut, Terra Gaia, Beltrano, ou similares) que envolvam direta ou indiretamente a marca $O$ Boticário, seus produtos, nomes de fornecedores ou terceiros, fica proibido qualquer tipo de intervençāo, vinculaçāo, divulgaçāo ou resposta de funcionários, franqueados, funcionários de franquias, terceiros, fornecedores. Estes, ao tomar conhecimento das comunidades online descritas acima e qualquer outro canal semelhante, deverāo comunicar imediatamente ao Centro de Relacionamento com Cliente, sendo esta a única área que poderá responder, intervir ou manifestar-se, em nome do Boticário, visto que possui expertise em relacionamento com o cliente.
\end{abstract}

Fonte: $<$ http/:www.orkut.com>

Réplica dos integrantes da comunidade ao comentário foi rápida e enérgica.

Quadro 5: Comentários enviados em seguida

\begin{tabular}{|c|c|}
\hline Usuário 1 & $\begin{array}{l}17 / 10 / 200616: 12 \\
\text { Postura totalmente desnecessária e desmotivante ao consumidor. Boticário } \\
\text { caiu no meu conceito legal agora ( } \mathrm{Pq} \text { sinceramente, saq é que nem político: } \\
\text { serve só para fazer a gente perder a paciência); }\end{array}$ \\
\hline Usuário 1 & $\begin{array}{l}17 / 10 / 200616: 13 \\
\text { Um absurdo isso, totalmente absurdo! }\end{array}$ \\
\hline Usuário 2 & $\begin{array}{l}18 / 10 / 200618.54 \\
\text { Ola... achei dsmotivant tb, pq querendo ou } \mathrm{n} \text { estamos trazendo cada vez mais } \\
\text { clientes para a marca } O \text { Boticario... aki tiramos duvidas de clientes e trocamos } \\
\text { informacoes sobre "somente" produtos da loja... } \mathrm{n} \text { achei q foi uma ideia muito } \\
\text { boa } \mathrm{n}, \Theta \mathrm{sim} \text { exagerada } \Theta \mathrm{sm} \text { necessidad disso.... mas seja feita a vossa } \\
\text { vontad... }\end{array}$ \\
\hline Usuário 3 & $\begin{array}{l}18 / 10 / 200620: 11 \\
\text { Aff que bobeira.... nao tamos falando preços e nada relativo. Só falando qual o } \\
\text { o perfume que cada } 1 \text { gosta e essas coisas!!! }\end{array}$ \\
\hline Usuário 4 & $\begin{array}{l}19 / 10 / 200611: 27 \\
\text { ai ai ai ... }\end{array}$ \\
\hline Usuário 5 & $\begin{array}{l}\text { 20/10/2006 06:07 } \\
\text { Puxa!!! }\end{array}$ \\
\hline Usuário 6 & $\begin{array}{l}20 / 10 / 200609: 27 \\
\text { Eu, heim!!! } \\
\text { Tudo isto se resume em duas palavras: PATÉTICO, RIDÍCULO. }\end{array}$ \\
\hline Usuário 7 & $\begin{array}{l}23 / 10 / 200617: 41 \\
\text { Ridiculo!!!! }\end{array}$ \\
\hline Usuário 8 & $\begin{array}{l}23 / 10 / 200619: 48 \\
\text { Coisa mais idiota } \\
\text { eu năo estou acreditando que perdi meu tempo lendo isso! }\end{array}$ \\
\hline Usuário 9 & $\begin{array}{l}29 / 10 / 200615: 37 \\
\text { ridiculo } \\
\text { Cada um tem direito de responder sobre os ótimos produtos. Essa empresa } \\
\text { caiu no conceito de muitos, será que náo entendem o quanto existem pessoas } \\
\text { que procuram informaçáo aqui no Orkut antes de ir a lojas, e se ninguém do } \\
\text { boticário responder, haverá muitas pessoas de outras marcas se aproveitando } \\
\text { disso para falar absurdos, como já existem por aí. Espero que essa brilhante } \\
\text { empresa mude essa conduta arbitrária.Pois Liberdade de Expressão e á } \\
\text { respostas claras sobre os produtos da marca. } \\
\text { Năo é năo? }\end{array}$ \\
\hline
\end{tabular}

Fonte: $<$ http/:www.orkut.com> 


\section{CONCLUSÃO}

Com a globalização, a internet se tornou um poderoso instrumento de comunicação entre diversos usuários de diversas partes do mundo. Com o seu avanço, vários programas e ferramentas foram criados para facilitar a troca de informações.

Surgiram sites pessoais e de relacionamentos, onde as pessoas têm a liberdade de relatar fatos, manifestar opiniões, dentre outras formas de publicação. Entretanto, essas ferramentas deixaram de ser usadas, única e exclusivamente por jovens em busca de diversão. O Orkut e os blogs, por exemplo, estão se tornando presentes no dia a dia dos mais variados tipos de pessoas e consequentemente, consumidores. Nesses novos espaços virtuais, os clientes, satisfeitos ou não, têm a liberdade de expor suas opiniões e idéias em relação as mais variadas empresas e aos seus produtos e serviços. Com esse vasto acesso às informações e facilidade de comparações, os consumidores, tem se tornado infiéis às empresas e às marcas.

Com isso, as organizações necessitam elaborar um sistema no qual enquadre os clientes em um bom serviço de atendimento, tanto no antes, durante ou no pós-compra, para poder fidelizá-los e conquistar novos.

Uma maneira encontrada para a fidelização de clientes, é acompanhar ou participar dos novos espaços na internet. 0 relacionamento com o cliente, por exemplo, pode ser estabelecido através desses espaços. Além do contado direto com o consumidor de forma rápida e dinâmica, a empresa também obtém a vantagem de poder observar os comentários e vê-los com fonte de informação sobre a aceitabilidade de seus produtos e serviços, podendo utilizálos para modificar, alterar ou substituir seu portfólio.

Entretanto, não se pode afirmar que as organizações definitivamente seguirão esta tendência, nem afirmar que esta é uma maneira ideal de observar o comportamento do consumidor. Todavia, muitas empresas estão estudando tal assunto. Com base no site da E-life, pode-se constatar que, aproximadamente 115 empresas já monitoram os comentários dos internautas nos espaços virtuais.

Então, as empresas precisam estar atentas às mudanças ocorridas a sua volta e, principalmente, na internet, antes que tenham sua marca e suas práticas afetadas pelo poder dessas novas ferramentas.

Logo, conclui-se que as organizações para se tornarem competitivas e tomarem a frente no mercado, precisam se preparar para as oportunidades ou ameaças provenientes de um mundo cada vez mais globalizado, em constante processo de mudança e com consumidores cada vez mais antenados com as novas tendências.

\section{BIBLIOGRAFIA}

BARELLA, Irene. Crescem as soluções que unem o call center à Web. Disponível em: <http://www.resellerweb.com.br/solutions/telecom/call_center/artigo.asp?id=15600>. Acesso em: 9 dez. 2006.

BEGARA, Thalula. Blogs invadem o mundo corporativo. Disponível em: <http://www.catho.com.br/jcs/inputer_view.phtml?id=7920>. Acesso em: 12 mai. 2006.

BENDER, Alessandro. CEM - Consumer Experience Management. Disponível em: <http://www.umacentral.com.br/content/view/91/30/>. Acesso em: 11 nov. 2006. 
BOONE, Louis E., KURTZ, David L. Marketing Contemporâneo. Rio de Janeiro: LTC, 1998.

BOTICÁRIO. Site corporativo. Disponível em:<http://www.boticario.com.br>. Acesso em: 7 set. 2006.

CHURCHILL Jr., Gilbert A.; PETER, J. Paul. Marketing: criando valor para os clientes. São Paulo: Saraiva, 2000.

COBRA, Marcos. Administração de Marketing. São Paulo: Atlas, 1992.

DIAS, Sérgio Roberto (Coord.) Gestão de Marketing. São Paulo: Saraiva, 2003.

E-LIFE. Site Corporativo (online). Disponível em:<http://www.elife.com.br>. Acesso em: 8 dez. 2006.

FIORE, Frank. E-Marketing Estratégico. São Paulo: MAKRON Books, 2001.

FURRIER, Marcio Tadeu. Miopia em Marketing, 4 Décadas Depois. Disponível em: <http://www.portaldomarketing.com.br/Artigos/Miopia\%20em\%20MKT\%204\%20decadas $\%$ 20depois.htm>. Acesso em: 4 out. 2006.

GRACIOSO, Francisco. Marketing, uma Experiência Brasileira. São Paulo: Cultrix, 1971.

GREENBERG, Paul. CRM, costumer relathionship management na velocidade da luz: conquista e lealdade de clientes em tempo real na Internet. Rio de Janeiro: Campus, 2001.

GUIMARÃES, Camila. Blogs: Sua empresa está nua. EXAME, São Paulo, ano 40, nº 2, p. 18-25, fev. 2006.

HERZOG, Ana Luiza. Blog também é marketing. EXAME, São Paulo, ano 40, n 13, p. 75, jul. 2006.

KENDZERSKI, Paulo Roberto. Como desenvolver um relacionamento eficiente com os clientes? Disponível em: <http://www.relacionamentodigital.com/como-desenvolverumrelacionamento-eficiente-com-os-clientes>. Acesso em: 9 dez. 2006.

KOTLER, Philip. Marketing. São Paulo: Atlas, 1992.

São Paulo: Atlas, 1998.

Administração de Marketing: análise, planejamento, implementação e controle.

$\underset{\text { Hall, } 2000 .}{ }$. Administração de Marketing: a edição do novo milênio. São Paulo: Prentice

LAS CASAS, Alexandre. Marketing. São Paulo: Atlas, 1997.

LEITE, Nildo. Pense bem ao fazer o Marketing da sua empresa. Disponível em: <http://www.estrategista.com/html/modules/eNoticias/article.php?articleID=635>. Acesso em 7 dez. 2006.

Objetividade em marketing. Disponível em: <http://www.estrategista.com/html/modules/eNoticias/article.php?articleID=657>. Acesso em 7 dez. 2006.

LIMA, Alessandro B. Blogs e Orkut serão o novo SAC? Disponível em: 
<http://www.e_life.blogger.com.br/2005_11_01_archive.html>. Acesso em: 12 mai. 2006.

MADRUGA, Roberto Pessoa. Administração de marketing no mundo contemporâneo/Roberto Pessoa Madruga, Bem Thion Chi, Marcos Licínio da Costa Simões, Ricardo Franco Teixeira. Rio de Janeiro: FGV, 2004.

MERINO, Danilo W. Internet: canal de comunicação com o consumidor. Disponível em: <http://www.relacionamentodigital.com/Internet-canal-de-comunicacao-com-oconsumidor>. Acesso em: 9 dez 2006.

MONTI, Roberto. É hora de gerar lucros para sua empresa. Disponível em: <http://www.acessa.com/negocios/arquivo/dicas/2002/02/25-Lucros/>. Acesso em: 11 nov. 2006.

MORAIS. Ricardo Prates. 0 marketing também acontece em blogs, chats, icq, msn, Orkut . Disponível em: <http://www.e<market.ppg.br/index.asp?InCdEditoria =23\&pagina=2\&InCdMateria=3933>. Acesso em: 12 mai. 2006.

MOREIRA DE SÁ, Cláudio Luiz. Contraponto nas centrais de atendimento: Tecnologia X Recursos Humanos. Disponível em: <http://carreiras.empregos.com.br/comunidades/rh/artigos/170603callcenter_rh_teclan.shtm>. Acesso em: 9 dez. 2006.

MULLER, Patrícia. Blogs corporativos: uma introdução. Disponível em: <http://www.sinestesia.co.uk/blog/?page_id=501> Acesso em: 12 mai. 2006

ORKUT. Site Corporativo (online). Disponível em: <http://www.Orkut.com>. Acesso em: 7 set. 2006.

PALLOTA, Leonardo. Fax, telefone e Internet? A ordem é integrar. Disponível em: <http://www.relacionamentodigital.com/marketing_de_clientes>. Acesso em: 9 dez. 2006.

PEPPERS, Don e ROGERS, Martha. AMA redefine o marketing: o que importa é o cliente. Disponível em: <http://www.1to1.com.br/newsletter/newsletter.php3?data=2004-1111\#1>. Acesso em: 19 out. 2006.

PICOLI, André Luís. Essencial perfumes. 2005. 76f. Trabalho (Pós-graduação em Gestão de Negócios) - Instituto Paulista de Ensino e Pesquisa, São Paulo, 2005. Disponível em: <http://www.ipep.edu.br/TCC/A\%20EMPRESA\%20ESSENCIAL\%20PERFUMES\%2018.06.pd f>. Acesso em: 18 dez. 2006.

POLESI, Cassiano. Veja o site de empresa como mídia. Disponível em: <http://www.aureliogalvao.jor.br/art/art025.htm> Acesso em: 4 out. 2006.

REIS, Abel. Blogs Corporativos. Disponível em: http://www.agenciaclick.com.br/br/estudos/artigo_1593.asp>. Acesso em: 7 set. 2006.

RICHERS, Raimar. 0 que é marketing. São Paulo: Brasiliense, 1986.

SALOMÃO, Alexa. Caçadores de fofocas. EXAME, São Paulo, ano 39, nº 18, p. 88-89, set. 2005.

SEIXAS, Fabio. Blogs corporativos no Brasil. $E$ no mundo. Disponível em: <http://blog.fabioseixas.com.br/archives/2006/01/blogs_corporati.html>. Acesso em: 12 
mai. 2006.

SERRA, Fernando A. Ribeiro. Administração estratégica: conceitos, roteiro prático e casos / Fernando A. Ribeiro Serra, Maria Cândida S. Torres, Alexandre Pavan Torres - Rio de Janeiro: Reichmann e Affonso Editores, 2004.

SILVA, Adriano. Afinal, o que é Marketing? Disponível em: <http://www.perspectivas.com.br/e3.htm>. Acesso em: 4 out. 2006.

SOARES, Anderson Eduardo. Customer Relationship Management. Disponível em: <http://www.anderson.eti.br/index.php?option=com_content\&task=view\&id=16\&Itemid=2> . Acesso em: 11 nov. 2006.

SOUZA, Edney. Blog Pessoal. Disponível em: <http://www.interney.net/?p=9754428>. Acesso em: 12 mai. 2006.

SOUZA, Michel de. A vez do Gerenciamento de Relações. Disponível em: <http://www.imasters.com.br/artigo/1648/bi/a_vez_do_gerenciamento_de_relacoes/>Acess o em: 11 Nov. 2006. 